\title{
Lipoprotein (a) and Stroke: An Overview
}

\author{
Leonidas Christogiannis, Haralampos J. Milionis* and Moses Elisaf
}

Department of Internal Medicine, School of Medicine, University of Ioannina, Ioannina, Greece

\begin{abstract}
Stroke remains a major cause of mortality and long term severe disability worldwide. Lipoprotein (a) [Lp(a)] is a predictor of many forms of vascular disease, and may serve as a tool in identifying subjects at risk. Despite accumulating evidence from cross sectional and prospective studies, its role in the development of stroke is still in doubt. Methodological issues regarding measurement remain to be resolved. Whether reductions in Lp(a) levels will result in a reduction of vascular events, including stroke, remains to be established. Aggressive management of established cardiovascular risk factors is advocated in subjects exhibiting elevated serum Lp(a) concentrations.
\end{abstract}

Keywords: Lipoprotein (a), vascular disease, stroke, cardiovascular risk.

\section{INTRODUCTION}

Stroke constitutes a leading cause of mortality and long term physical and mental disability [1]. Annually, 15 million people worldwide suffer a stroke. Of these, 5 million die and another 5 million are left permanently disabled, placing a burden on family and community [2]. There are well established risk factors for stroke, such as increased blood pressure, increased blood cholesterol, cigarette smoking, carotid stenosis, diabetes mellitus, atrial fibrillation and valvular heart disease. There is a reasonably reliable evidence to suggest that $60-80 \%$ of all ischemic strokes can be attributed to these risk factors [3]. There is an accumulating evidence that emerging biological markers, including lipoprotein (a) $[\mathrm{Lp}(\mathrm{a})]$, add to the prognostic value of conventional risk factors and may well serve as useful prognostic tools in identifying subjects at risk [4].

$\mathrm{Lp}(\mathrm{a})$ is a plasma lipoprotein which was identified in 1963 [5] and exhibits high structural similarity with low density lipoprotein (LDL) cholesterol. Both lipoproteins are characterized by the same lipid composition and the presence apolipoprotein (apo) B-100. Their specific distinction consists of glucoprotein apo(a), which is present only in $\mathrm{Lp}(\mathrm{a})$. Apo(a) is attached to apoB-100 by a disulphide bridge [6]. The cDNA sequence of apo(a) was determined in 1987 and found to share great similarity with plasminogen, containing multiple copies of plasminogen kringle 4, a single copy of plasminogen kringle 5 and an inactive protease domain [7]. There are 34 different-sized apo(a) isoforms [8]. The apo(a) gene is estimated to be the most responsible for the wide variance of plasma $\mathrm{Lp}$ (a) levels in general population [9].

There is an evidence that $\operatorname{Lp}(\mathrm{a})$ is a predictor of many forms of vascular disease, including premature coronary, peripheral and cerebral artery disease $[10,11]$. We briefly

*Address correspondence to this author at the Department of Internal Medicine, School of Medicine, University of Ioannina, 451 10Ioannina, Greece; Tel: +30 2651097516; Fax: +30 2651097016; E-mail: hmilioni@uoi.gr review the factors determining $\operatorname{Lp}$ (a) levels and the mechanisms involved in $\mathrm{Lp}$ (a)-promoted atherogenicity with regard to the pathogenesis of stroke as well as the the potential for pharmacologic manipulation of $\operatorname{Lp}(\mathrm{a})$ levels.

\section{METHODS OF DATA RESEARCH}

We scanned all possibly relevant articles in the electronic databases MEDLINE, EMBASE (with links to participating online journals) and other related databases. Our research covered all languages and the years between January 1960 and August 2009. The keywords were stroke, cerebrovascular accident, cerebrovascular disease, lipoprotein (a), apolipoprotein (a) and $\mathrm{Lp}(\mathrm{a})$.

\section{MODULATION OF LIPOPROTEIN (a) LEVELS}

$\mathrm{Lp}$ (a) levels in plasma vary widely among individuals and they are under strong genetic determination [9]. There is also a difference of $L p(a)$ levels between certain ethnic groups. It has been found that African populations exhibit higher plasma Lp(a) levels as compared to Caucasian populations [12].

Although, concentrations of $\mathrm{Lp}(\mathrm{a})$ in plasma are highly resistant to changes from environmental factors [13], they can be influenced by certain metabolic abnormalities and pharmacological agents. Lipid lowering drugs, such as statins and fibrates have almost no impact on Lp(a) levels [10]. Interestingly, another lipid lower agent, nicotinic acid in high doses, as well as LDL apheresis and hormone replacement therapy with estrogen, have been shown to lower Lp(a) levels [14]. $L p(a)$ levels may be increased in the end stage renal disease [15], acute phase response [16], diabetes mellitus [17], cancer [18] and hypothyroidism [19], and in contrary they may be decreased in liver failure [20], hyperthyroidism [21], renal transplantation in patients with the end stage renal disease [15], in patients with severe infections [22-24] and after administration of L-carnitine [25], levothyroxine [26] or soy protein [27]. 


\section{ROLE OF LIPOPROTEIN (a) IN THE PATHOGENE- SIS OF ATHEROTHROMBOSIS}

The structural similarity of Lp(a) with LDL gives to this lipoprotein a possible proatherosclerotic role. $\mathrm{Lp}$ (a) participates in the atherosclerotic process. It is possible that there is a contribution of $\mathrm{Lp}(\mathrm{a})$ in the atherosclerotic plaque formation, supported by an evidence showing that there is an accumulation of $\mathrm{Lp}(\mathrm{a})$ in the atherosclerotic lesions [28]. Its plaque levels correlate with its concentration in the plasma [29]. Lp(a) accumulates in plaques more avidly than LDL [29], it can be oxidized and lead to foam cell formation within the vascular wall after its uptake by macrophages [30].

There is an evidence that $\mathrm{Lp}$ (a) might exert proinflammatory actions. It stimulates the chemotaxis of macrophages and co-localizes with them within atherosclerotic plaques [31]. Lp(a) stimulates the secretion of interleukin 6 by monocytes [32] and the expression of adhesion molecules by endothelial cells [33]. It also inhibits the activation of the anti-inflammatory cytokine-transforming growth factor $\beta$ (TGF- $\beta$ ) [34]. $L p(a)$ appears to be a preferential carrier of proinflammatory oxidized E06 phospholipids [35] which have been shown to predict the presence and progression of carotid and femoral atherosclerosis [36]. Lp(a) also stimulates the proliferation of vascular smooth muscle cells within atherosclerotic lesions [37].

The striking homology between $\mathrm{Lp}$ (a) and plasminogen is indicative of the role of $\mathrm{Lp}(\mathrm{a})$ as a possible prothrombotic risk factor. It has been proposed that $\mathrm{Lp}$ (a) has the ability to inhibit fibrinolysis by competing for plasminogen binding in different systems [38]. Lp(a) might also propagate atherothrombosis by inhibiting platelet-mediated fibrinolysis and modulating platelet activation and aggregation [39]. It has also been found that $\mathrm{Lp}(\mathrm{a})$ may constitute an independent risk factor for venous thromboembolism [40]. There is a data that $\mathrm{Lp}(\mathrm{a})$ inhibits the production of tissue-type plasminogen activator (tPA) [41] and stimulate the synthesis of plasminogen activator inhibitor-1 (PAI-1) [42].

\section{LIPOPROTEIN (a) AND CORONARY ARTERY DIS- EASE}

Many studies have shown an evidence concerning the role of $\mathrm{Lp}(\mathrm{a})$ in the pathogenesis of coronary artery disease (CAD) [43-45]. The unique structure of Lp(a), as we mentioned, gives to this lipoprotein thrombogenic and atherogenic properties that can explain the mechanism through which $\mathrm{Lp}(\mathrm{a})$ may increase the risk of CAD[46].

Two large meta-analyses came to provide interesting data about this issue. A meta-analysis of 27 prospective studies, with information on 5436 CAD cases, leaded to the conclusion that people in the general population with plasma $\mathrm{Lp}$ (a) levels at the top third of baseline measurement are at $70 \%$ increased risk of CAD as compared with those in the bottom third [47]. The investigators of this meta-analysis didn't find strong correlation between $\mathrm{Lp}$ (a) levels and other well established risk factors for CAD. Another meta-analysis of 14 prospective studies showed that $\mathrm{Lp}(\mathrm{a})$ concentrations are higher in subjects who later develop CAD, than in those who do not, and this effect is similar in men and women [48].
An analysis of the Lp(a) levels of 2,047 patients who had first ever nonfatal myocardial infarction or who died of CAD and 3,921 control participants from the Reykjavik Study resulted to the conclusion that there are independent, continuous associations between $\mathrm{Lp}$ (a) levels and risk of future CAD in a broad range of individuals [49].

In a recent study involving 3 cohorts of white individuals of Danish descent followed up through 1991 to 2007 ( $n=40486,2824$ myocardial infarction events), a causal association between elevated Lp(a) levels and increased risk of myocardial infarction was documented [50].

\section{LIPOPROTEIN (a) AND PERIPHERAL VASCULAR DISEASE}

Concerning the relationship between $\mathrm{Lp}$ (a) levels and peripheral vascular disease (PVD), many studies have provided interesting findings. There are strong evidence that $\mathrm{Lp}$ (a) is a significant independent risk factor for PVD and that elevated Lp(a) levels may be associated with more severe forms of PVD [51-54].

Few studies yet have studied the role of $\mathrm{Lp}(\mathrm{a})$ in the pathogenesis of abdominal aortic aneurysm. There are few evidences that there may be an association [55, 56]. However, more studies are needed in order to define this role.

\section{LIPOPROTEIN (a) AND ATHEROSCLEROTIC DIS- EASE OF THE CAROTID ARTERIES}

Regarding the role of $\mathrm{Lp}(\mathrm{a})$ in atherosclerosis of the carotid arteries, it has been shown that $\mathrm{Lp}(\mathrm{a})$ is not associated with early atherogenesis of the carotid arteries [57, 58]. In patients with heterozygous hypercholesterolemia, Lp(a) levels did not correlate with the progression of carotid artery atherosclerosis, as assessed by measuring carotid intimamedia thickness (IMT) [36]. Nevertheless, Lp(a) seems to be strongly associated with carotid stenosis and occlusion, but not with carotid plaque area, possibly because of its prothrombotic capacity [59].

\section{ELEVATED Lp(a) LEVELS AS A RISK FACTOR OF STROKE}

Several cross sectional (and a few prospective) studies provide contradictory findings regarding $L p(a)$ as a predictor of ischemic stroke $[10,11]$. A recent meta-analysis tried to combine the data from the available literature in order to define the possible association of $\operatorname{Lp}(\mathrm{a})$ with stroke. The data analysis from 31 studies with 56010 subjects and >4,609 stroke events concluded that $\mathrm{Lp}(\mathrm{a})$ is a risk factor for cerebrovascular disease (CeVD) [60].

\section{Studies Failing to Show any Associations of $\operatorname{Lp(a)}$ and Stroke}

Alfthan et al. conducted a prospective study based on 7,424 Finnish subjects, free of atherosclerotic disease at baseline, and concluded that there is no association between $\mathrm{Lp}$ (a) levels and the risk of atherosclerotic disease (myocardial infarction or stroke) [61].

The analysis of the baseline $\mathrm{Lp}$ (a) levels of 14,916 men, who had no clinical atherosclerotic disease at baseline and who were followed up for 7.5 years, showed no association 
between $\mathrm{Lp}$ (a) plasma concentration and risk of total or thromboembolic stroke [62].

A community-based cohort of 9,936 individuals with 841 CeVD events concluded that $\mathrm{Lp}(\mathrm{a})$ is a weak risk factor for $\mathrm{CeVD}$ in men and not a significant predictor of CeVD risk in women [63].

A nested case-control study determined plasma Lp(a) levels of 101 patients with history of ischemic stroke and 201 matched control subjects and suggested that there is no association between baseline plasma $\mathrm{Lp}$ (a) levels and future ischemic stroke [64].

The role of $\mathrm{Lp}(\mathrm{a})$ as a risk factor for ischemic stroke in young women was under investigation in The Stroke Prevention In Young Women Study. Lp(a) levels of 110 young women (15-44 years of age) with cerebral infarction and 216 age-matched controls were measured and showed no association of $\mathrm{Lp}(\mathrm{a})$ plasma concentration with stroke in this population group [65].

Another study compared Lp(a) levels of 94 patients aged 15-45 years with acute ischemic stroke, with 111 agematched controls and did not find any differences. It is of interest that in this study a very low rate of angiographically evident atherosclerosis was detected (3.2\%) [66].

The Edinburgh Artery study followed 1,592 healthy individuals for 5 years. The incidence of stroke was $3.7 \%$, but raised $\mathrm{Lp}$ (a) levels at baseline were not significantly associated with increased risk for stroke (relative risk, RR: 1.24)[67].

\section{Studies in Favor of an Association of Lp(a) with Stroke}

Early studies showed that elevated plasma Lp(a) levels are associated with increased risk of cerebrovascular disease $[68,69]$. Since, the determination of cDNA sequence and a number of studies came to provide more evidences regarding this association.

Van Kooten et al. measured Lp(a) concentration in plasma from 151 patients with acute ischemic stroke and followed them up for a mean period of $2.5+/-1.2$ years. The results showed that $\mathrm{Lp}(\mathrm{a})$ is increased in about one third of patients with acute ischemic stroke, but it is not associated with the cardiovascular risk profile, stroke characteristics or the prognosis of these patients [70].

In another prospective study, 3,972 older adults (65 years of age or older) free of vascular disease were followed for a median of 7.4 years. This study concluded that $\mathrm{Lp}(\mathrm{a})$ is an independent predictor for stroke in older man but not in older women [71].

In the Prospective Study Of Pravastatin In The Elderly At Risk (PROSPER), 5,732 individuals provided baseline fresh samples for measurement of the $\mathrm{Lp}$ (a) concentration and were followed for 3.2 years on average. There was no significant association between $\mathrm{Lp}(\mathrm{a})$ levels and risk for CVD events (RR:1.04, p:0.38) [72].

A population-based case-control study compared Lp(a) plasma concentration of 163 patients with first-ever-in-alifetime acute ischemic non-embolic stroke and 166 healthy subjects and concluded that stroke patients exhibited higher
Lp(a) concentrations $(\mathrm{p}<0.001)$ associated with a higher prevalence of small apo (a) isoforms [73].

In a prospective study with a follow up period of 32 years, 2,313 men were enrolled at the age of 50. At the end of the follow up period 421 incidence stroke had occurred. The analysis of Lp(a) plasma concentration concluded that $\mathrm{Lp}$ (a) constitutes an independent risk factor for stroke [74].

The Atherosclerosis Risk in Communities (ARIC) study enrolled 14,221 subjects of both sexes and after a follow-up period of 13.5 years, there were 496 incident ischemic strokes. The analysis of the baseline levels of $\mathrm{Lp}$ (a) concluded that participants with $\mathrm{Lp}(\mathrm{a})>300 \mu \mathrm{g} / \mathrm{ml}$ had a $79 \%$ increased age, sex, and race-adjusted hazard ratio of ischemic stroke than did those with $\mathrm{Lp}(\mathrm{a})<100 \mu \mathrm{g} / \mathrm{ml}$. There was an association of $\mathrm{Lp}(\mathrm{a})$ with the incidence of ischemic stroke in black and white women and in black men, but not in white men [75].

Sharobeem et al. assessed Lp(a) concentration and Apo B to ApoAI ratio in 55 South Asian subjects with ischemic stroke and 85 controls. The analysis of the data showed that both parameters were associated with ischemic stroke [76].

Rigal et al. compared Lp(a) levels between 100 patients with acute ischemic stroke and 100 healthy subjects and noted that even a slight elevation in $\mathrm{Lp}$ (a) plasma concentration was strongly and independently associated with ischemic stroke in men, but not in women [77].

The role of $\mathrm{Lp}(\mathrm{a})$ in silent cerebral infarction (SCI) was investigated in patients with chronic renal failure who were maintained on hemodialysis. Lp(a) was found to be significantly associated with the presence of SCI [78].

Dhamija et al. studied the role of homocysteine and $\mathrm{Lp}(\mathrm{a})$ in ischemic stroke. They determined plasma Lp(a) concentration in 66 patients with ischemic stroke and 72 controls and found that these two parameters are independently associated with ischemic stroke with a significant positive correlation between them [79].

\section{THERAPEUTIC INTERVENTIONS TO LOWER Lp(a) LEVELS}

Diet is not thought to influence $\operatorname{Lp}(\mathrm{a})$ values to any great extent. However, saturated and n-3 polyunsaturated fatty acids may slightly reduce $L p(a)$ values. Thus, a diet rich in palm oil has been reported to reduce $\mathrm{Lp}(\mathrm{a})$ concentrations by approximately $10 \%$ [80]. Long term administration of n-3 polyunsaturated fatty acids may reduce $\mathrm{Lp}(\mathrm{a})$ values by as much as $20 \%$ [81].

Patients with hypothyroidism tend to have higher Lp(a) levels, which fall after establishing a euthyroid state [82]. Preliminary data suggest that thyroid hormone receptor-beta selective agonists, which are being developed for the treatment of obesity, may also reduce Lp(a) levels [83].

Fibrates reduced $\mathrm{Lp}$ (a) levels in some studies but had no effect in others [84].

The effects of statins on $\mathrm{Lp}(\mathrm{a})$ levels are inconsistent [10]. Some studies suggested that Lp(a) might be a more potent risk factor in patients with elevated LDL-cholesterol levels $[85,86]$. This might provide a rationale for treating patients with elevated LDL-cholesterol and Lp(a) levels with 
statins. Data from the Familial Atherosclerosis Treatment Study (FATS), which included patients with high levels of $\mathrm{Lp}(\mathrm{a})$, suggested that reducing LDL-cholesterol by $40 \%$ abolished any excess risk because of elevated $\mathrm{Lp}(\mathrm{a})$ concentrations, but it should be noted that niacin was used in the treatment of regimen in this study [87].

Niacin (nicotinic acid) appears to consistently decrease $\mathrm{Lp}$ (a) levels by $20-25 \%$ and is currently the first-choice therapy to specifically reduce $\mathrm{Lp}$ (a) levels [88].

The antisense therapy to apoB100 mipomersen and microsomal transfer protein inhibitors [5] have also been shown to reduce $\mathrm{Lp}(\mathrm{a})$ by $30-40 \%$ [89].

The choice of antihypertensive agent might also affect Lp(a) levels. Atenolol might increase Lp(a) levels, whereas other beta blockers did not have this effect [90]. Calcium channel blockers and inhibitors of the renin-angiotensin system have been reported to lower serum Lp(a) [91].

Finally, in patients with established atherosclerotic vascular disease, including patients with ischemic stroke aspirin induces a reduction in $\mathrm{Lp}$ (a) levels, particularly in those with elevated serum Lp(a) levels [92, 93].

\section{CONCLUSION}

There is an evidence suggesting a role for $L p(a)$ in the development of vascular disease. However, Studies determining its significance as a risk factor for stroke, have produced conflicting results. The lack of universally accepted standardized methods obviates its wide use as a screening tool to identify patients at risk [94]. It remains to be established whether reductions in $\mathrm{Lp}(\mathrm{a})$ levels will result in a reduction of vascular events, including stroke. A well-advised strategy would involve aggressive management of established cardiovascular risk factors in subjects presenting with elevated serum $\mathrm{Lp}(\mathrm{a})$ concentrations.

\section{REFERENCES}

[1] Bonita, R. Epidemiology of stroke. Lancet, 1992, 339(8789), 342344.

[2] WHO, ww.who.int/cardiovascular_diseases/en/cvd_atlas_15_burden_stroke.pdf

[3] Hankey, G. J. Potential new risk factors for ischemic stroke: what is their potential? Stroke, 2006, 37(8), 2181-2188.

[4] Erqou, S.; Kaptoge, S.; Perry, P. L.; Di Angelantonio, E.; Thompson, A.; White, I. R.; Marcovina, S. M.; Collins, R.; Thompson, S. G.; Danesh, J. Lipoprotein(a) concentration and the risk of coronary heart disease, stroke, and nonvascular mortality. JAMA, 2009, 302(4), 412-423.

[5] Berg, K. A new serum type system in man--the Lp System. Acta Pathol. Microbiol. Scand., 1963, 59, 369-382.

[6] Scanu, A. M. Lp(a) lipoprotein--coping with heterogeneity. $N$. Engl. J. Med., 2003, 349(22), 2089-2090.

[7] McLean, J. W.; Tomlinson, J. E.; Kuang, W. J.; Eaton, D. L.; Chen, E. Y.; Fless, G. M.; Scanu, A. M.; Lawn, R. M. cDNA sequence of human apolipoprotein(a) is homologous to plasminogen. Nature, 1987, 330(6144), 132-137.

[8] Gaw, A.; Hobbs, H. H. Molecular genetics of lipoprotein (a): new pieces to the puzzle. Curr. Opin. Lipidol., 1994, 5(2), 149-155.

[9] Boerwinkle, E.; Leffert, C. C.; Lin, J.; Lackner, C.; Chiesa, G.; Hobbs, H. H. Apolipoprotein(a) gene accounts for greater than $90 \%$ of the variation in plasma lipoprotein(a) concentrations. J. Clin. Invest., 1992, 90(1), 52-60.

[10] Tziomalos, K.; Athyros, V. G.; Wierzbicki, A. S.; Mikhailidis, D. P. Lipoprotein a: where are we now? Curr. Opin. Cardiol., 2009, 24(4), 351-357.
[11] Milionis, H. J.; Winder, A. F.; Mikhailidis, D. P. Lipoprotein (a) and stroke. J. Clin. Pathol., 2000, 53(7), 487-496.

[12] Sandholzer, C.; Hallman, D. M.; Saha, N.; Sigurdsson, G.; Lackner, C.; Csaszar, A.; Boerwinkle, E.; Utermann, G. Effects of the apolipoprotein(a) size polymorphism on the lipoprotein(a) concentration in 7 ethnic groups. Hum. Genet., 1991, 86(6), 607-614.

[13] McCormick, S. P. Lipoprotein (a): biology and clinical importance. Clin. Biochem. Rev., 2004, 25(1), 69-80.

[14] Crouse, J. R. 3rd. New developments in the use of niacin for treatment of hyperlipidemia: new considerations in the use of an old drug. Coron . Artery Dis., 1996, 7(4), 321-326.

[15] Rosas, S.; Joffe, M.; Wolfe, M.; Brayman, K.; Rader, D. J. Effects of renal replacement therapy on plasma lipoprotein(a) levels. Am. J. Nephrol., 2008, 28(3), 361-365.

[16] Craig, W. Y.; Ledue, T. B. Lipoprotein(a) and the acute phase response. Clin. Chim. Acta, 1992, 210(3), 231-232.

[17] Bruckert, E.; Davidoff, P.; Grimaldi, A.; Truffert, J.; Giral, P.; Doumith, R.; Thervet, F.; De Gennes, J. L. Increased serum levels of lipoprotein(a) in diabetes mellitus and their reduction with glycemic control. JAMA, 1990, 263(1), 35-36.

[18] Wright, L. C.; Sullivan, D. R.; Muller, M.; Dyne, M.; Tattersall, M. H.; Mountford, C. E. Elevated apolipoprotein(a) levels in cancer patients. Int. J. Cancer, 1989, 43(2), 241-244.

[19] Engler, H.; Riesen, W. F. Effect of thyroid function on concentrations of lipoprotein(a). Clin. Chem., 1993, 39(12), 2466-2469.

[20] Feely, J.; Barry, M.; Keeling, P. W.; Weir, D. G.; Cooke, T. Lipoprotein(a) in cirrhosis. BMJ, 1992, 304(6826), 545-546.

[21] Kung, A. W.; Pang, R. W.; Lauder, I.; Lam, K. S.; Janus, E. D. Changes in serum lipoprotein(a) and lipids during treatment of hyperthyroidism. Clin. Chem., 1995, 41(2), 226-231.

[22] Liberopoulos, E.; Apostolou, F.; Elisaf, M. Serum lipid profile in patients with severe leptospirosis. Nephrol. Dial. Transplant., 2004, 19(5), 1328-1329.

[23] Liberopoulos, E.; Alexandridis, G.; Bairaktari, E.; Elisaf, M. Severe hypocholesterolemia with reduced serum lipoprotein(a) in a patient with visceral leishmaniasis. Ann. Clin. Lab Sci., 2002, 32(3), 305-308.

[24] Milionis, H. J.; Mittari, V.; Exarchakos, G.; Kalaitzidis, R.; Skevas, A. T.; Elisaf, M. S. Lipoprotein (a) and acute-phase response in patients with vestibular neuronitis. Eur. J. Clin. Invest., 2003, 33(12), 1045-1050.

[25] Derosa, G.; Cicero, A. F.; Gaddi, A.; Mugellini, A.; Ciccarelli, L.; Fogari, R. The effect of L-carnitine on plasma lipoprotein(a) levels in hypercholesterolemic patients with type 2 diabetes mellitus. Clin. Ther., 2003, 25(5), 1429-1439.

[26] Milionis, H. J.; Efstathiadou, Z.; Tselepis, A. D.; Bairaktari, E. T.; Tsironis, L. D.; Tsatsoulis, A.; Elisaf, M. S. Lipoprotein (a) levels and apolipoprotein (a) isoform size in patients with subclinical hypothyroidism: effect of treatment with levothyroxine. Thyroid, 2003, 13(4), 365-369.

[27] Meinertz, H.; Nilausen, K.; Hilden, J. Alcohol-extracted, but not intact, dietary soy protein lowers lipoprotein(a) markedly. Arterioscler. Thromb. Vasc. Biol., 2002, 22(2), 312-316.

[28] Rath, M.; Niendorf, A.; Reblin, T.; Dietel, M.; Krebber, H. J.; Beisiegel, U. Detection and quantification of lipoprotein(a) in the arterial wall of 107 coronary bypass patients. Arteriosclerosis, 1989, 9(5), 579-592.

[29] Pepin, J. M.; O'Neil, J. A.; Hoff, H. F. Quantification of apo[a] and apoB in human atherosclerotic lesions. J. Lipid Res., 1991, 32(2), 317-327.

[30] Tsimikas, S.; Tsironis, L. D.; Tselepis, A. D. New insights into the role of lipoprotein(a)-associated lipoprotein-associated phospholipase A2 in atherosclerosis and cardiovascular disease. Arterioscler. Thromb. Vasc. Biol., 2007, 27(10), 2094-2099.

[31] Syrovets, T.; Thillet, J.; Chapman, M. J.; Simmet, T. Lipoprotein(a) is a potent chemoattractant for human peripheral monocytes. Blood, 1997, 90(5), 2027-2036.

[32] Buechler, C.; Ullrich, H.; Aslanidis, C.; Bared, S. M.; Lingenhel, A.; Ritter, M.; Schmitz, G. Lipoprotein (a) downregulates lysosomal acid lipase and induces interleukin-6 in human blood monocytes. Biochim. Biophys. Acta, 2003, 1642(1-2), 25-31.

[33] Allen, S.; Khan, S.; Tam, S.; Koschinsky, M.; Taylor, P.; Yacoub, M. Expression of adhesion molecules by $\operatorname{lp}(\mathrm{a})$ : a potential novel mechanism for its atherogenicity. FASEB J., 1998, 12(15), 17651776. 
[34] Grainger, D. J.; Kemp, P. R.; Liu, A. C.; Lawn, R. M.; Metcalfe, J. C. Activation of transforming growth factor-beta is inhibited in transgenic apolipoprotein(a) mice. Nature, 1994, 370(6489), 460462 .

[35] Tsimikas, S.; Brilakis, E. S.; Miller, E. R.; McConnell, J. P.; Lennon, R. J.; Kornman, K. S.; Witztum, J. L.; Berger, P. B. Oxidized phospholipids, Lp(a) lipoprotein, and coronary artery disease. $N$. Engl. J. Med., 2005, 353(1), 46-57.

[36] Tsimikas, S.; Kiechl, S.; Willeit, J.; Mayr, M.; Miller, E. R.; Kronenberg, F.; Xu, Q.; Bergmark, C.; Weger, S.; Oberhollenzer, F.; Witztum, J. L. Oxidized phospholipids predict the presence and progression of carotid and femoral atherosclerosis and symptomatic cardiovascular disease: five-year prospective results from the Bruneck study. J. Am. Coll. Cardiol., 2006, 47(11), 2219-2228.

[37] Ichikawa, T.; Unoki, H.; Sun, H.; Shimoyamada, H.; Marcovina, S.; Shikama, H.; Watanabe, T.; Fan, J. Lipoprotein(a) promotes smooth muscle cell proliferation and dedifferentiation in atherosclerotic lesions of human apo(a) transgenic rabbits. Am. J. Pathol., 2002, 160(1), 227-236.

[38] Aznar, J.; Estelles, A.; Breto, M.; Espana, F. Euglobulin clot lysis induced by tissue type plasminogen activator in subjects with increased levels and different isoforms of lipoprotein (a). Thromb. Res., 1993, 72(5), 459-465.

[39] Tsironis, L. D.; Mitsios, J. V.; Milionis, H. J.; Elisaf, M.; Tselepis, A. D. Effect of lipoprotein (a) on platelet activation induced by platelet-activating factor: role of apolipoprotein (a) and endogenous PAF-acetylhydrolase. Cardiovasc. Res., 2004, 63(1), 130-138.

[40] Marcucci, R.; Liotta, A. A.; Cellai, A. P.; Rogolino, A.; Gori, A. M.; Giusti, B.; Poli, D.; Fedi, S.; Abbate, R.; Prisco, D. Increased plasma levels of lipoprotein(a) and the risk of idiopathic and recurrent venous thromboembolism. Am. J. Med., 2003, 115(8), 601605.

[41] Levin, E. G.; Miles, L. A.; Fless, G. M.; Scanu, A. M.; Baynham, P.; Curtiss, L. K.; Plow, E. F. Lipoproteins inhibit the secretion of tissue plasminogen activator from human endothelial cells. Arterioscler. Thromb., 1994, 14(3), 438-442.

[42] Li, X. N.; Grenett, H. E.; Benza, R. L.; Demissie, S.; Brown, S. L.; Tabengwa, E. M.; Gianturco, S. H.; Bradley, W. A.; Fless, G. M.; Booyse, F. M. Genotype-specific transcriptional regulation of PAI1 expression by hypertriglyceridemic VLDL and Lp(a) in cultured human endothelial cells. Arterioscler. Thromb. Vasc. Biol., 1997, 17(11), 3215-3223.

[43] Berg, K.; Dahlen, G.; Christophersen, B.; Cook, T.; Kjekshus, J.; Pedersen, T. Lp(a) lipoprotein level predicts survival and major coronary events in the Scandinavian Simvastatin Survival Study. Clin. Genet., 1997, 52(5), 254-261.

[44] Seman, L. J.; DeLuca, C.; Jenner, J. L.; Cupples, L. A.; McNamara, J. R.; Wilson, P. W.; Castelli, W. P.; Ordovas, J. M.; Schaefer, E. J. Lipoprotein(a)-cholesterol and coronary heart disease in the Framingham Heart Study. Clin. Chem., 1999, 45(7), 1039-1046.

[45] Luc, G.; Bard, J. M.; Arveiler, D.; Ferrieres, J.; Evans, A.; Amouyel, P.; Fruchart, J. C.; Ducimetiere, P. Lipoprotein (a) as a predictor of coronary heart disease: the PRIME Study. Atherosclerosis, 2002, 163(2), 377-384.

[46] Koschinsky, M. L. Lipoprotein(a) and the link between atherosclerosis and thrombosis. Can. J. Cardiol., 2004, 20(Suppl B), 37B43B.

[47] Danesh, J.; Collins, R.; Peto, R. Lipoprotein(a) and coronary heart disease: meta-analysis of prospective studies. Circulation, 2000, 102(10), 1082-1085.

[48] Craig, W. Y.; Neveux, L. M.; Palomaki, G. E.; Cleveland, M. M.; Haddow, J. E. Lipoprotein(a) as a risk factor for ischemic heart disease: metaanalysis of prospective studies. Clin. Chem., 1998, 44(11), 2301-2306.

[49] Bennet, A.; Di Angelantonio, E.; Erqou, S.; Eiriksdottir, G.; Sigurdsson, G.; Woodward, M.; Rumley, A.; Lowe, G. D.; Danesh, J.; Gudnason, V. Lipoprotein(a) levels and risk of future coronary heart disease: large-scale prospective data. Arch. Intern. Med., 2008, 168(6), 598-608.

[50] Kamstrup, P. R.; Tybjaerg-Hansen, A.; Steffensen, R.; Nordestgaard, B. G. Genetically elevated lipoprotein(a) and increased risk of myocardial infarction. JAMA, 2009, 301(22), 2331-2339.

[51] Valentine, R. J.; Kaplan, H. S.; Green, R.; Jacobsen, D. W.; Myers, S. I.; Clagett, G. P. Lipoprotein (a), homocysteine, and hypercoagulable states in young men with premature peripheral atherosclero- sis: a prospective, controlled analysis. J. Vasc. Surg., 1996, 23(1), 53-61, discussion 61-53.

[52] Cheng, S. W.; Ting, A. C.; Wong, J. Lipoprotein (a) and its relationship to risk factors and severity of atherosclerotic peripheral vascular disease. Eur. J. Vasc. Endovasc. Surg., 1997, 14(1), 17-23.

[53] Widmann, M. D.; Sumpio, B. E. Lipoprotein (a): a risk factor for peripheral vascular disease. Ann. Vasc. Surg., 1993, 7(5), 446-451.

[54] Jones, G. T.; van Rij, A. M.; Cole, J.; Williams, M. J.; Bateman, E. H.; Marcovina, S. M.; Deng, M.; McCormick, S. P. Plasma lipoprotein(a) indicates risk for 4 distinct forms of vascular disease. Clin. Chem., 2007, 53(4), 679-685.

[55] Schillinger, M.; Domanovits, H.; Ignatescu, M.; Exner, M.; Bayegan, K.; Sedivy, R.; Polterauer, P.; Laggner, A. N.; Minar, E.; Kostner, K. Lipoprotein (a) in patients with aortic aneurysmal disease. J. Vasc. Surg., 2002, 36(1), 25-30.

[56] Sofi, F.; Marcucci, R.; Giusti, B.; Pratesi, G.; Lari, B.; Sestini, I. Lo Sapio, P.; Pulli, R.; Pratesi, C.; Abbate, R.; Gensini, G. F. High levels of homocysteine, lipoprotein (a) and plasminogen activator inhibitor-1 are present in patients with abdominal aortic aneurysm. Thromb. Haemost., 2005, 94(5), 1094-1098.

[57] Grebe, M. T.; Schoene, E.; Schaefer, C. A.; Boedeker, R. H.; Kemkes-Matthes, B.; Voss, R.; Tillmanns, H. H. Elevated lipoprotein(a) does not promote early atherosclerotic changes of the carotid arteries in young, healthy adults. Atherosclerosis, 2007, 190(1), 194198.

[58] Sramek, A.; Reiber, J. H.; Baak-Pablo, R.; Sturk, A.; Rosendaal, F. R. Lipoprotein(a) and ultrasonographically determined early atherosclerotic changes in the carotid and femoral artery. J. Thromb. Haemost., 2003, 1(2), 374-379.

[59] Klein, J. H.; Hegele, R. A.; Hackam, D. G.; Koschinsky, M. L.; Huff, M. W.; Spence, J. D. Lipoprotein(a) is associated differentially with carotid stenosis, occlusion, and total plaque area. Arterioscler. Thromb. Vasc. Biol., 2008, 28(10), 1851-1856.

[60] Smolders, B.; Lemmens, R.; Thijs, V. Lipoprotein (a) and stroke: a meta-analysis of observational studies. Stroke, 2007, 38(6), 19591966.

[61] Alfthan, G.; Pekkanen, J.; Jauhiainen, M.; Pitkaniemi, J.; Karvonen, M.; Tuomilehto, J.; Salonen, J. T.; Ehnholm, C. Relation of serum homocysteine and lipoprotein(a) concentrations to atherosclerotic disease in a prospective Finnish population based study. Atherosclerosis, 1994, 106(1), 9-19.

[62] Ridker, P. M.; Stampfer, M. J.; Hennekens, C. H. Plasma concentration of lipoprotein(a) and the risk of future stroke. JAMA, 1995, 273(16), 1269-1273

[63] Nguyen, T. T.; Ellefson, R. D.; Hodge, D. O.; Bailey, K. R.; Kottke, T. E.; Abu-Lebdeh, H. S. Predictive value of electrophoretically detected lipoprotein(a) for coronary heart disease and cerebrovascular disease in a community-based cohort of 9936 men and women. Circulation, 1997, 96(5), 1390-1397.

[64] Glader, C. A.; Stegmayr, B.; Boman, J.; Stenlund, H.; Weinehall, L.; Hallmans, G.; Dahlen, G. H. Chlamydia pneumoniae antibodies and high lipoprotein(a) levels do not predict ischemic cerebral infarctions: results from a nested case-control study in Northern Sweden. Stroke, 1999, 30(10), 2013-2018.

[65] Wityk, R. J.; Kittner, S. J.; Jenner, J. L.; Hebel, J. R.; Epstein, A.; Wozniak, M. A.; Stolley, P. D.; Stern, B. J.; Sloan, M. A.; Price, T. R.; McCarter, R. J.; Macko, R. F.; Johnson, C. J.; Earley, C. J.; Buchholz, D. W.; Schaefer, E. J. Lipoprotein (a) and the risk of ischemic stroke in young women. Atherosclerosis, 2000, 150(2), 389-396.

[66] Albucher, J. F.; Ferrieres, J.; Ruidavets, J. B.; Guiraud-Chaumeil, B.; Perret, B. P.; Chollet, F. Serum lipids in young patients with ischaemic stroke: a case-control study. J. Neurol. Neurosurg. Psychiatry, 2000, 69(1), 29-33.

[67] Price, J. F.; Lee, A. J.; Rumley, A.; Lowe, G. D.; Fowkes, F. G. Lipoprotein (a) and development of intermittent claudication and major cardiovascular events in men and women: the Edinburgh Artery Study. Atherosclerosis, 2001, 157(1), 241-249.

[68] Murai, A.; Miyahara, T.; Fujimoto, N.; Matsuda, M.; Kameyama, M. Lp(a) lipoprotein as a risk factor for coronary heart disease and cerebral infarction. Atherosclerosis, 1986, 59(2), 199-204.

[69] Jurgens, G.; Koltringer, P. Lipoprotein(a) in ischemic cerebrovascular disease: a new approach to the assessment of risk for stroke. Neurology, 1987, 37(3), 513-515. 
[70] van Kooten, F.; van Krimpen, J.; Dippel, D. W.; Hoogerbrugge, N.; Koudstaal, P. J. Lipoprotein(a) in patients with acute cerebral ischemia. Stroke, 1996, 27(7), 1231-1235.

[71] Ariyo, A. A.; Thach, C.; Tracy, R. Lp(a) lipoprotein, vascular disease, and mortality in the elderly. N. Engl. J. Med., 2003, 349(22), 2108-2115.

[72] Gaw, A.; Murray, H. M.; Brown, E. A. Plasma lipoprotein(a) [Lp(a)] concentrations and cardiovascular events in the elderly: evidence from the prospective study of pravastatin in the elderly at risk (PROSPER). Atherosclerosis, 2005, 180(2), 381-388.

[73] Milionis, H. J.; Filippatos, T. D.; Loukas, T.; Bairaktari, E. T.; Tselepis, A. D.; Elisaf, M. S. Serum lipoprotein(a) levels and apolipoprotein(a) isoform size and risk for first-ever acute ischaemic nonembolic stroke in elderly individuals. Atherosclerosis, 2006, 187(1), 170-176.

[74] Wiberg, B.; Sundstrom, J.; Arnlov, J.; Terent, A.; Vessby, B.; Zethelius, B.; Lind, L. Metabolic risk factors for stroke and transient ischemic attacks in middle-aged men: a community-based study with long-term follow-up. Stroke, 2006, 37(12), 2898-2903.

[75] Ohira, T.; Schreiner, P. J.; Morrisett, J. D.; Chambless, L. E.; Rosamond, W. D.; Folsom, A. R. Lipoprotein(a) and incident ischemic stroke: the Atherosclerosis Risk in Communities (ARIC) study. Stroke, 2006, 37(6), 1407-1412.

[76] Sharobeem, K. M.; Patel, J. V.; Ritch, A. E.; Lip, G. Y.; Gill, P. S.; Hughes, E. A. Elevated lipoprotein (a) and apolipoprotein B to AI ratio in South Asian patients with ischaemic stroke. Int. J. Clin. Pract., 2007, 61(11), 1824-1828.

[77] Rigal, M.; Ruidavets, J. B.; Viguier, A.; Petit, R.; Perret, B.; Ferrieres, J.; Larrue, V. Lipoprotein (a) and risk of ischemic stroke in young adults. J. Neurol. Sci., 2007, 252 (1), 39-44.

[78] Fukunaga, N.; Anan, F.; Kaneda, K.; Nawata, T.; Saikawa, T.; Yoshimatsu, H. Lipoprotein (a) as a risk factor for silent cerebral infarction in hemodialysis patients. Metabolism, 2008, 57(10), 1323-1327.

[79] Dhamija, R. K.; Gaba, P.; Arora, S.; Kaintura, A.; Kumar, M.; Bhattacharjee, J. Homocysteine and lipoprotein (a) correlation in ischemic stroke patients. J. Neurol. Sci., 2009, 281(1-2), 64-68.

[80] Hornstra, G.; van Houwelingen, A. C.; Kester, A. D.; Sundram, K. A palm oil-enriched diet lowers serum lipoprotein(a) in normocholesterolemic volunteers. Atherosclerosis, 1991, 90(1), 91-93.

[81] Schmidt, E. B.; Klausen, I. C.; Kristensen, S. D.; Lervang, H. H.; Faergeman, O.; Dyerberg, J. The effect of n-3 polyunsaturated fatty acids on Lp(a). Clin. Chim. Acta, 1991, 198(3), 271-277.

[82] Pearce, E. N. Hypothyroidism and dyslipidemia: modern concepts and approaches. Curr. Cardiol. Rep., 2004, 6(6), 451-456.

[83] Grover, G. J.; Mellstrom, K.; Malm, J. Therapeutic potential for thyroid hormone receptor-beta selective agonists for treating obesity, hyperlipidemia and diabetes. Curr. Vasc. Pharmacol., 2007, 5(2), 141-154.
[84] Filippatos, T.; Milionis, H. J. Treatment of hyperlipidaemia with fenofibrate and related fibrates. Expert Opin. Investig. Drugs, 2008, 17(10), 1599-1614.

[85] von Eckardstein, A.; Schulte, H.; Cullen, P.; Assmann, G. Lipoprotein(a) further increases the risk of coronary events in men with high global cardiovascular risk. J. Am. Coll. Cardiol., 2001, 37(2), 434-439.

[86] Kronenberg, F.; Kronenberg, M. F.; Kiechl, S.; Trenkwalder, E.; Santer, P.; Oberhollenzer, F.; Egger, G.; Utermann, G.; Willeit, J. Role of lipoprotein(a) and apolipoprotein(a) phenotype in atherogenesis: prospective results from the Bruneck study. Circulation, 1999, 100(11), 1154-1160.

[87] Maher, V. M.; Brown, B. G.; Marcovina, S. M.; Hillger, L. A.; Zhao, X. Q.; Albers, J. J. Effects of lowering elevated LDL cholesterol on the cardiovascular risk of lipoprotein(a). JAMA, 1995, 274(22), 1771-1774.

[88] Scanu, A. M.; Bamba, R. Niacin and lipoprotein(a): facts, uncertainties, and clinical considerations. Am. J. Cardiol., 2008, 101(8A), 44B-47B.

[89] Merki, E.; Graham, M. J.; Mullick, A. E.; Miller, E. R.; Crooke, R. M.; Pitas, R. E.; Witztum, J. L.; Tsimikas, S. Antisense oligonucleotide directed to human apolipoprotein B-100 reduces lipoprotein(a) levels and oxidized phospholipids on human apolipoprotein B-100 particles in lipoprotein(a) transgenic mice. Circulation, 2008, 118 (7), 743-753.

[90] Rizos, E.; Bairaktari, E.; Kostoula, A.; Hasiotis, G.; Achimastos, A.; Ganotakis, E.; Elisaf, M.; Mikhailidis, D. P. The combination of nebivolol plus pravastatin is associated with a more beneficial metabolic profile compared to that of atenolol plus pravastatin in hypertensive patients with dyslipidemia: a pilot study. J. Cardiovasc. Pharmacol. Ther., 2003, 8(2), 127-134.

[91] Papadakis, J. A.; Ganotakis, E. S.; Jagroop, I. A.; Mikhailidis, D. P.; Winder, A. F. Effect of hypertension and its treatment on lipid, lipoprotein(a), fibrinogen, and bilirubin levels in patients referred for dyslipidemia. Am. J. Hypertens., 1999, 12(7), 673-681.

[92] Akaike, M.; Azuma, H.; Kagawa, A.; Matsumoto, K.; Hayashi, I.; Tamura, K.; Nishiuchi, T.; Iuchi, T.; Takamori, N.; Aihara, K.; Yoshida, T.; Kanagawa, Y.; Matsumoto, T. Effect of aspirin treatment on serum concentrations of lipoprotein(a) in patients with atherosclerotic diseases. Clin. Chem., 2002, 48(9), 1454-1459.

[93] Ranga, G. S.; Kalra, O. P.; Tandon, H.; Gambhir, J. K.; Mehrotra, G. Effect of aspirin on lipoprotein(a) in patients with ischemic stroke. J. Stroke Cerebrovasc. Dis., 2007, 16(5), 220-224.

[94] Marcovina, S. M.; Koschinsky, M. L.; Albers, J. J.; Skarlatos, S. Report of the national heart, lung, and blood institute workshop on lipoprotein(a) and cardiovascular disease: recent advances and future directions. Clin. Chem., 2003, 49 (11), 1785-1796.

(C) Christogiannis et al.; Licensee Bentham Open.

This is an open access article licensed under the terms of the Creative Commons Attribution Non-Commercial License (http://creativecommons.org/licenses/ by-nc/3.0/) which permits unrestricted, non-commercial use, distribution and reproduction in any medium, provided the work is properly cited. 